\title{
Bibliotecário escolar: um mediador de leitura
}

\author{
School librarian: a mediator reading
}

\author{
Ana Lúcia Antunes de Oliveira Bicheri \\ Mestre em Ciência da Informação pela Universidade Estadual Paulista Júlio de Mesquita Filho. \\ Bibliotecária da Faculdade Norte Paranaense de Ensino. \\ E-mail: donanalucia@yahoo.com.br
}

\begin{abstract}
Oswaldo Francisco Almeida Júnior Doutor em Ciências da Comunicação pela Universidade de São Paulo - USP. Professor associado da Universidade Estadual de Londrina e Professor Titular do programa de pós-graduação em Ciência da Informação da Universidade Estadual Paulista Júlio de Mesquita Filho - UNESP/Marília.

E-mail: ofaj@ofaj.com.br
\end{abstract}

\section{Resumo}

Discorre sobre a biblioteca e o bibliotecário escolar. Apresenta a biblioteca escolar como um espaço propício ao desenvolvimento de atividades promotoras de leitura. Elenca o perfil e as características do bibliotecário escolar, destacando a importância de seu envolvimento com a comunidade escolar; sua necessária educação continuada e imprescindível atuação como bibliotecário-leitor na formação de leitores.

Palavras-chave: Biblioteca escolar. Bibliotecário escolar. Formação de leitores.

\begin{abstract}
Discusses the library and the school librarian. Displays the school library as a space conducive to the development of activities that promote reading. It lists the profile and characteristics of the school librarian, highlighting the importance of their involvement with the school community; their required continuing education and essential role as librarian-reader in forming readers.
\end{abstract}

Keywords: School library. School librarian. Formation of readers.

\section{Introdução}

Falar em formação de leitores é algo necessário, principalmente num espaço e tempo de novos suportes e incontáveis possibilidades de leitura; e consequentemente, um novo leitor.

Um momento em que, apesar de tantos recursos e informações ainda se percebe que uma parcela representativa da população não vê na leitura uma necessidade ou um prazer em seu cotidiano.

$\mathrm{Na}$ formação do leitor é imprescindível que haja, a princípio, pessoas envolvidas a meios/recursos para o desenvolvimento de gosto e competência para a leitura. 
Este texto discorre sobre a biblioteca escolar e a contribuição do bibliotecário escolar na formação do leitor.

\section{Biblioteca e bibliotecário escolar}

Para discorrer sobre o bibliotecário escolar e a formação de leitores é pertinente que se tenha antes uma noção de biblioteca e bibliotecário escolar.

Vale lembrar a importância da biblioteca escolar na formação da criança, na formação do leitor e a imensa contribuição do bibliotecário nesta tarefa, um bibliotecário-leitor, que goste de ler, que contagie os alunos e os estimule a ler.

Embora pesquisas revelem o discurso acima, a biblioteca escolar ainda é de certa forma, um mito em muitas escolas brasileiras.

Por outro lado, principalmente na rede particular de ensino há grandes iniciativas a esse respeito e mais ainda se faz necessário a participação do bibliotecário em tal processo de transformação de imagem da biblioteca escolar.

É preciso que o bibliotecário conheça sua responsabilidade nessa tarefa e atue de forma a contribuir para a formação de leitores.

Em busca da independência e autonomia na leitura, favorecendo a parceria de professor e bibliotecário, a biblioteca escolar é um local privilegiado para a formação de leitores.

Principalmente se lembrarmos que um grande número de brasileiros só tem acesso a livros e outras fontes/recursos de leitura na biblioteca. Ela precisa "existir" na escola e cumprir seu papel. A biblioteca escolar

[...] é uma instituição do sistema escolar que organiza materiais bibliográficos, audiovisuais e outros meios e os coloca a disposição de uma comunidade educacional. Constitui parte integrante do sistema educativo e participa de seus objetivos, metas e fins. A Biblioteca é um instrumento de desenvolvimento do currículo e permite o fomento da leitura e a formação de uma atividade científica, constitui um elemento que forma o indivíduo para a aprendizagem permanente, estimula a criatividade, a comunicação, facilita a recreação, apóia os docentes em sua capacitação e lhes oferece informação necessária para a tomada de decisão em aula. Trabalha também com os pais de família e com outros agentes da comunidade. (CASTRILLON apud MAYRINK, 1992, p.50) 
Deve contar com espaço, ambiente e acervo que promovam a leitura e atendam as necessidades informacionais dos alunos, professores e demais membros da escola.

O senso comum percebe a biblioteca como local onde se organiza, conserva e disponibiliza livros. Não está errado, porém é importante lembrar que à medida que surgem novos suportes de informação e documentação a biblioteca precisa se atualizar e alterar sua atuação na sociedade. Isso tem acontecido, mas não tem sido dado a conhecer o suficiente.

Segundo Obata (1999) a biblioteca deve ser vista também como um espaço de produção de cultura.

Junto a este conceito é pertinente citar que algumas bibliotecas, procurando atuar de forma mais integrada, heterogênea e pluralizada, unindo diferentes recursos aos tradicionais textos e materiais da biblioteca, acabaram por mudar sua denominação. Algumas por exemplo adotam "CRA" Centro de Recursos para a Aprendizagem ou Centro de Recursos de Aprendizagem como denominação. Outras colocam na porta de entrada "Biblioteca-CRA". Este último, pode-se notar, está em fase de transição de denominação e conceito em sua comunidade.

Mas a maioria, com certeza é denominada Biblioteca Escolar.

A simples existência de uma biblioteca escolar, bem localizada, de bom tamanho, bem decorada, com um grande acervo atualizado não é suficiente para atender as necessidades da comunidade escolar e contribuir para a qualidade do ensino e formação do aluno.

Para que a biblioteca escolar possa cumprir com seu papel é necessário, além de espaço e acervo, de um bibliotecário competente e engajado na escola como um todo. Importa, e muito, a qualidade das atividades, as atitudes tomadas pelo bibliotecário, que deve ser competente, comunicativo, interessado e criativo.

Muitos educadores sabem da importância da biblioteca, mas desconhecem a importância do bibliotecário. Por isso o profissional que atua na biblioteca não pode ficar no seu cantinho, esperando que os usuários (professores, alunos, funcionários, direção e pais de alunos) se dirijam até ele.

Ele deve ir ao encontro de seus usuários, procurar saber o que eles precisam, o que gostam, o que querem, quais são seus interesses, necessidades e expectativas. Conhecendo-os, há condições de mostrar-lhes o que de bom se pode fazer por eles e com eles. 
O bibliotecário escolar (leitor, mediador e educador), inserido em sua comunidade, tem como uma de suas atividades, participar do projeto pedagógico atuando junto a professores, alunos, funcionários e familiares de alunos, num trabalho de cooperação e participação, de forma a tornar a biblioteca escolar um espaço dinâmico na escola, favorecendo o processo de ensino-aprendizagem.

De acordo com Barros (1986) espera-se que o bibliotecário: tenha competência técnica, não seja passivo em seu trabalho, assuma uma postura política, acumule cultura, exerça a autocrítica, não seja um mero guardião de livros e respeite o leitor, muito mais carente de saber do que de técnicas.

Junto ao conceito acima se deve acrescentar a responsabilidade de mediação que se confere ao bibliotecário já que ele está entre a escola e a biblioteca, entre o aluno e o acesso à leitura.

Este profissional tem responsabilidade para com a escola e sua função de mediador favorece, entre outros aspectos, a seleção, organização, disponibilização do acervo/informações e intervenção nas práticas de leitura no ambiente em que atua, também contribuindo na formação de leitores.

Ao bibliotecário escolar não bastam conhecimentos técnicos da área de biblioteconomia, educação e leitura. Ele precisa se envolver com sua comunidade, saber e gostar de trabalhar com crianças, adolescentes e adultos.

Além de sua formação acadêmica, que tem por obrigação lhe oferecer os conhecimentos necessários ao desenvolvimento de seu trabalho, o bibliotecário escolar tem como preocupação realimentar seus conhecimentos e habilidades com uma educação continuada, ou seja, procurar manter-se informado e atualizado tanto em sua área profissional quanto na parte pedagógica por meio de leituras, palestras, reuniões e cursos entre outros.

É imprescindível que, independente do ambiente e de influências educacionais, políticas, sociais, e culturais, o bibliotecário seja, antes de tudo, um leitor. Um leitor incondicional e permanente dos assuntos ligados à sua área profissional, de atuação específica e também de modo geral a temas referentes às questões sociais, políticas e econômicas de maneira a atuar de forma relevante e competente em seu meio, procurando sempre redimensionar suas atividades de acordo com a realidade, mudanças e necessidades de sua comunidade. 
Seu bom desempenho depende de sua postura diante dos obstáculos, de sua competência técnica e de sua consciência com relação a seu papel de mediador, agente social, crítico e transformador na sociedade.

É importante e necessário que o bibliotecário, pelo trabalho em parceria, por meio de atividades criativas, pela disponibilização do acervo e outros recursos da biblioteca, motive seus usuários e lhes proporcione o alcance dos benefícios do tesouro que pode e deve ser a leitura.

Atualmente, frente a tantos avanços tecnológicos, imagens e meios de comunicação de massa, algumas pessoas trocam uma boa leitura por outras formas de lazer. Neste contexto, incutir nas crianças o prazer da leitura deve constituir uma das prioridades e desafios do bibliotecário. Ele não pode deixar que a correria e as dificuldades encontradas no ambiente escolar o façam estacionar em seu trabalho e expectativas.

Mas o que se percebe na realidade brasileira é que isto é bastante citado na teoria e dificilmente visto na prática.

Em geral, as bibliotecas escolares, quando existem, na maioria das vezes são precárias, não contam com um profissional bibliotecário e não oferecem condições para o desenvolvimento de atividades que correspondam a seu potencial de atuação social citado na teoria.

O que acontece é que em muitas salas "chamadas bibliotecas" há um professor, um funcionário administrativo ou geral trabalhando e sendo conhecido como bibliotecário. Silva e Bortolin (2006, p.12) atentam para uma discussão relacionada a isso.

[...] muita crítica tem sido feita sobre o professor ocupar o espaço do bibliotecário na escola. Por outro lado, com a mesma intensidade se fala do despreparo pedagógico do bibliotecário para atuar na biblioteca das escolas. Corporativismo a parte, pouco se tem feito para resolver esse impasse e a biblioteca escolar, em especial na esfera pública, não progride. Ineficiente, permanece ausente da vida dos estudantes. Sofre do mal da invisibilidade, quase ninguém percebe sua falta. [...]

Algumas escolas possuem biblioteca e bibliotecário, mas pode-se dizer que um número muito pequeno de bibliotecários se destaca e tem seu trabalho reconhecido pela comunidade escolar. Mesmo porque alguns bibliotecários não alcançam os objetivos pretendidos por eles mesmos e esperados pela escola. 
Por vezes atuam apenas de forma tecnicista, acomodada e apática, sem assumir seu verdadeiro papel, sem agir concreta e politicamente com propostas para formação do leitor e promoção da leitura e acesso à cultura.

Pior ainda, este profissional, cercado de recursos de leitura, em alguns casos lê pouco ou praticamente não lê. Na década de 1980, no Brasil já havia uma preocupação quanto a isso. Barros (1986, p.30) já dizia que

[...] o bibliotecário que não lê se castra consciente ou inconscientemente. Não avança e não promove conhecimento. Não se arma para os imprevistos do dia-a-dia, como que esquecendo que a biblioteca é palco de incontáveis dúvidas, que a sua cultura pode ajudar a resolver. Sendo o bibliotecário um profissional da informação, por excelência, não pode, ele próprio, estar alheio aos fatos e às notícias. É essa constante atualização do conhecimento, repito, que faz do seu referencial teórico uma base segura de apoio ao leitor a que está vinculado. [...]

Os antigos currículos dos cursos de Biblioteconomia eram muito técnicos e não ofereciam a capacitação necessária a este profissional para trabalhar em biblioteca escolar, já que para atuar neste tipo de biblioteca o bibliotecário precisa além de conhecimentos técnicos de biblioteconomia, saber um pouco dos processos de pedagogia, pois lida com crianças e adolescentes.

Hoje, ainda que pouco, alguns currículos oportunizam parte deste tipo de noção. Porém, no momento de estágios, por exemplo, nem todos os alunos têm oportunidade de vivenciar a realidade de uma biblioteca escolar.

Isto é um entrave para a atuação do bibliotecário quando vai trabalhar em uma biblioteca escolar. Aí novamente se repete a importância do bibliotecário escolar possuir a competência, qualidade, característica e envolvimento. Vejamos então um pouco da contribuição do bibliotecário escolar na formação de leitores.

\section{Bibliotecário escolar e sua contribuição na formação de leitores}

O bibliotecário escolar é um educador ainda pouco citado na história da leitura no Brasil. Apesar de na década de 80 já existirem trabalhos publicados sobre o bibliotecário, a leitura e o leitor, Sidoti ([2002?], p. web) afirma que a partir da década de 90 é que

[...] as pesquisas começaram a enfocar novos papéis do bibliotecário e da biblioteca pública ou escolar. Esta deixa de ser somente um espaço silencioso para busca de informações, e passa a constituir um espaço para cativar leitores, pela mediação dos 
bibliotecários, que deixam de ser meros guardiões de livros ou orientadores de pesquisa, assumindo o papel de contadores de histórias também. [...]

Pode-se perceber que a discussão sobre a participação do bibliotecário na formação do leitor em escolas é ainda recente com relação à história da leitura e por isso mesmo deve ser analisada, avaliada, desenvolvida...

Diferentemente dos professores, o bibliotecário não tem como incumbência primeira cumprir conteúdos curriculares, grade curricular, etc.

Sua participação na formação do leitor, no prazer da leitura deve se desprender da cobrança de leitura para aquisição de conteúdos ou normas gramaticais.

Almeida Junior (2006, p.53-54) discorrendo sobre a postura do bibliotecário escolar menciona que o bibliotecário adequado é aquele que

[...] está em constante questionamento; [...] que procura conhecer sua área de atuação; [...] que tem consciência de que o usuário é seu fim último; que sabe que as informações com as quais lida não são neutras e imparciais; que está sempre procurando conhecer os motivos que há por trás de suas ações; [...] que sabe que a informação é imprescindível para a formação do cidadão. O bibliotecário escolar é aquele que reconhece sua profissão como importante e necessária para a sociedade e se reconhece como um agente de transformação social. [...]

Questionar-se, conhecer sua área de atuação, ter a satisfação do usuário como fim, lidar com informações que não são neutras e imparciais, colaborando para a formação do cidadão realmente são atitudes que fazem do bibliotecário escolar um importante agente de transformação social.

O bibliotecário escolar, como mediador, deve estar inserido na comunidade escolar, conhecer e participar das propostas curriculares e fazer da biblioteca um espaço integrado a escola, proporcionando momentos de descoberta, alegria, criatividade, reflexões, debates, questionamentos, aprendizagem e prazer, entre outros.

Precisa gostar de crianças, de adolescentes, de jovens, de adultos, de idosos, enfim, deve gostar e saber lidar com pessoas de diferentes idades, pois como se sabe, a comunidade escolar é formada principalmente pelos alunos (crianças e adolescentes), mas também por direção, funcionários administrativos e gerais, professores e familiares de alunos. Em alguns casos, pessoas dos arredores da escola também.

Este tipo de bibliotecário apresenta particularidades que o diferencia de bibliotecários que não atuam na biblioteca escolar. Martins e Bortolin (2006, p.35) dizem que as ações do bibliotecário escolar,

Bibl. Esc. em Rev., Ribeirão Preto, v. 2, n. 1, p. 41-54, 2013. 
[...] se encontram mais próximas dos pedagogos e demais educadores, pois sobre ele recai a preocupação em dividir a responsabilidade de educar e de apoiar a escola no cumprimento do seu Projeto Político Pedagógico. Sendo assim, esse gênero de bibliotecário, além de conhecer as técnicas que lhes foram transmitidas durante sua formação, deve apresentar qualidades que o possibilite promover de fato a leitura. $[\ldots]$

Em se tratando especificamente da contribuição na formação de leitores sua responsabilidade é grande e maravilhosa. Um "desafio" é bem verdade, pois não se restringe aos conhecimentos recebidos e vivenciados na graduação. Mas é com certeza uma atividade gratificante.

Um dos requisitos é ser leitor e dar testemunho disso aos alunos; não só disponibilizar leitura aos seus usuários, mas também propor-lhes leituras. Outro é unir-se ao professor e demais membros da comunidade escolar fazendo-se conhecer e colocando a disposição seu conhecimento, interesse, habilidade e competência.

Isso porque muitos membros da escola não sabem quem é o bibliotecário e o que ele pode fazer na escola e pela escola como um todo.

Mas por outro lado, também o bibliotecário, a princípio não conhece a parte pedagógica e por isso mesmo precisa inteirar-se da área educacional, adquirindo novos conhecimentos por meio de leituras, encontros e conversas com educadores, reuniões, palestras e cursos entre outros. Enfim, este é um dos momentos em que o bibliotecário deve praticar a autocrítica e cumprir com a necessária educação continuada.

A partir daí é que pode participar ativamente e com segurança dos projetos referentes ao tema e colaborar, interferindo e sugerindo metas e estratégias.

Voltando a formação de leitores e promoção de leitura, vale lembrar que o trabalho do bibliotecário não é neutro, nem isolado. Cabe ao professor e ao bibliotecário estabelecer uma parceria, unindo esforços, imaginação e criatividade em várias atividades, para esse fim. Silva (2003, p.91-92) fala sobre a necessidade dessa parceria:

[...] cabe a esses dois profissionais - professor e bibliotecário - ler e fazer ler. Repetindo: cabe ler e fazer ler. Isto quer dizer que, para abraçar qualquer dessas duas profissões, o sujeito tem que ser leitor, encarnando em si as práticas de leitura como um valor absoluto e, por ter que fazer ler, tem que projetar e inculcar esse valor em todos os membros da sua comunidade através de projetos, programas e ações. [...] Quando os dois (professor e bibliotecário), atuando juntos, construírem boas estradas para que o leitor efetivamente dialogue assiduamente com esse "mestre dos mestres" [livro], ou seja, com aquele que por si só ensina sem a intermediação de mais ninguém, então resultará desse processo a inserção da criança e do jovem num outro patamar sócio-educacional, qual seja o patamar da independência e autonomia em leitura. 
A afirmação acima engloba resumidamente parte do objetivo fim deste item: "formar leitores que alcancem o patamar da independência e autonomia em leitura". Podemos acrescentar aí o prazer. E cita requisitos para a obtenção do resultado esperado. O requisito primeiro é que bibliotecário e professor sejam leitores. O objetivo segundo é fazer ler.

Para a realização de projetos de leitura vários itens devem ser levantados. Alguns deles são mencionados a seguir.

Tanto o bibliotecário quanto o professor precisam ter conhecimento de alguns pontos sobre a leitura e ter em mente que tipo de leitura querem promover. A leitura mecânica (o ledor) ou a leitura crítica (o leitor), a leitura como meio ou como fim?, "instalar e desenvolver o hábito de leitura?" ou "formar o gosto pela leitura e por meio dele construir outras leituras?"

Os projetos devem facilitar a relação entre o aluno, o leitor e o texto. Portanto, além de conhecer aspectos e materiais da escrita, da arte e da leitura, dos processos de ensino, do projeto pedagógico, da cultura e da sociedade, é impreterível que o mediador conheça a comunidade escolar, pois é com/para ela que se deve desenvolver os projetos.

Neste caso, os mediadores precisam ter conhecimento das fases do desenvolvimento humano, dos aspectos e características próprios a cada idade, das complexas relações e vínculos da criança e do adolescente com a família, com a escola, com a leitura e em geral o mundo que a cerca.

Professor e bibliotecário, trabalhando juntos devem buscar mais informações e objetivos, porém, cada qual terá responsabilidades e atividades específicas, empenhando-se no que sua formação e experiência o permitem fazer melhor. Silva $(1988$, p.5) fala um pouco sobre uma suposta divisão de responsabilidade.

[...] sem querer cair no radicalismo em termos de divisão social do trabalho, percebo especificamente [posturas] nítidas no trabalho escolar e no trabalho das bibliotecas. $\mathrm{O}$ primeiro deve fornecer as condições necessárias para que a criança aprenda a ler no sentido de participar ativamente do mundo da escrita. O segundo deve unir-se ou integrar-se ao primeiro, numa relação horizontal de cooperação, no sentido que a criança aprimore as suas capacidades de leitura e pratique em sua vida o ler para aprender.[...]

É necessário que haja integração e cooperação, proporcionando inclusive crescimento de ambas as partes, mesmo que algumas atividades sejam realizadas em conjunto e outras em 
separado. O importante é que haja entre esses leitores mediadores uma relação flexível e em sintonia com o desenvolvimento pedagógico da escola em favor do leitor.

Alguns cuidados devem ser tomados por ambos quanto ao empecilho colocado pela exigência autoritária da leitura na escola. Seria ótimo que a criança se aproximasse do livro como a um brinquedo, com prazer e sem cobranças. Silva (2006, p.77) nos atenta para isso ao dizer que na escola,

[...] quase nunca a leitura é livremente vivida, há sempre algo a fazer com ela: desenhos, provas, resumos, pinturas, redações, etc. É como se cada vez que assistíssemos um filme, tivéssemos que escrever ou pintar algo a respeito. Enfim, nós não fazemos isso quando estamos nos divertindo, então, porque a escola insiste em manter a leitura com essa atitude de 'desprazer'? (grifo do autor)

Com certeza o autor não quer dizer que não se deva programar atividades a ser desenvolvidas com relação à leitura, mas que não seja todas as vezes. Mesmo porque há um número representativo de pessoas que alcançam ótimos resultados fazendo uso de atividades pós-leitura.

Neste sentido a biblioteca é um ambiente mais propício a dar liberdade ao aluno, já que este não se sente avaliado pelo bibliotecário.

Assim, o bibliotecário pode e deve desenvolver atividades que envolvam a leitura na biblioteca com e sem o professor.

O bibliotecário, como já mencionado tem sua participação na formação do leitor e no prazer da leitura, desprendida da cobrança de leitura para aquisição de conteúdos ou normas gramaticais. Mas deve se prender a outros fatores.

Em uma de suas funções como, por exemplo, a indicação de um livro para um aluno, deve antes se lembrar das diferentes características da criança e do adolescente.

Indicando uma leitura que desperte o interesse do aluno o bibliotecário poderá proporcionar-lhe uma primeira experiência prazerosa com a leitura ou mesmo mantê-la naqueles que já a vivenciam.

Assim também deve ser no planejamento de projetos. Um projeto para cada tema, um projeto para cada fase, para diferentes objetivos e assim por diante.

Um dos cuidados que o bibliotecário deve ter na aproximação do leitor com o objeto de leitura é a organização do espaço da biblioteca; do tipo e da disposição dos móveis, acervo, 
cor, decoração, ventilação, iluminação e comunicação visual do ambiente, de forma que esse espaço seja aconchegante, prazeroso e convidativo.

Procurando irradiar alegria e bem estar, é responsável pela ambientação da criança e do adolescente num espaço onde circulam diferentes meios de leitura integrados com o plano pedagógico, motivando a leitura de livros, revistas e jornais, entre outros.

O leitor em potencial precisa ter acesso ao material de leitura. Cabe ao bibliotecário organizar a biblioteca de forma a permitir este acesso, objetivando a formação e ampliação do quadro de leitores, trabalhando com o conceito e incentivo à leitura sem excluir, censurar ou privilegiar qualquer tipo de leitura.

Quando se fala em não censurar qualquer tipo de leitura não se quer dizer que um livro com texto destinado a um adulto deva ser emprestado a uma criança das séries iniciais. É importante indicar textos que respeitem a necessidade de fantasia e imaginação da criança. $\mathrm{O}$ bibliotecário escolar precisa ser também um leitor de leitores, conforme afirma Battles (2003, p.150) quanto ao crescimento e desenvolvimento de hábitos de leitura.

[...] da mesma forma que o erudito começou com histórias infantis e foi progredindo aos poucos, passando pelos livros de aventura, romances, biografias, livros de viagem e, finalmente, livros de história, os novos leitores deveriam seguir o mesmo caminho, levando a sociedade toda junto com eles. A determinação do lugar de cada leitor nessa escala evolutiva estaria a cargo do bibliotecário. É esse o papel que ele deve desempenhar na vida dos que freqüentam uma biblioteca. Babás educam crianças, e bibliotecários educam leitores. Leitores lêem livros, bibliotecários lêem leitores. [...]

Nessa educação e leitura de leitores o bibliotecário há de cuidar muito bem da seleção do acervo fazendo com que este seja composto de textos de qualidade, que mexam com as emoções, dúvidas e angústias de seus leitores; que levem a criança e o adolescente gradativamente e em diferentes momentos à imaginação, fantasia, reflexão, questionamento, descoberta e senso crítico.

A "interferência", a mediação do bibliotecário na biblioteca, na escola, no incentivo à leitura encontra-se também em pequenos detalhes como a aparentemente simples definição de prazo para devolução de um livro, quantos livros podem ser emprestados, estabelecer ou não multa pelo atraso na devolução ou dano ao acervo; ao número de vezes e horário permitido para se frequentar a biblioteca. 
A mediação do bibliotecário com relação a seu comportamento com os alunos é importantíssima para a formação do gosto pela leitura. Bortolin (2006, p.71) afirma que o bibliotecário,

[...] além de respeitar as características e as necessidades dos usuários de hoje, deve estabelecer limites, sem autoritarismo, para que a criança e o adolescente possam ter, não apenas livre acesso às estantes, mas também espaço de liberdade para imaginar, indagar e inquietar, maravilhando-se com suas descobertas. [...]

São várias as atividades que podem ser desenvolvidas para incentivar a leitura, como: hora do conto, exposições, concursos literários, oficinas de leitura, murais informativos, feiras de livros, leitura \& arte na biblioteca, formação de contadores de história, divulgação do acervo (pelo bibliotecário e por alunos), divulgação de leitura, divulgação de lançamentos de editoras, história da escola ou do bairro, debate sobre autores e livros, varal de poesias, entre outros.

É importante que as atividades façam parte de um projeto de atividades, que na medida do possível colaborem ou estejam inseridas no planejamento e/ou realidade da escola.

Algumas escolas não possuem estrutura e número de funcionários suficiente para a realização de grandes e arrojados projetos, mas o importante é que sejam desenvolvidas atividades planejadas, com empenho, conhecimento e criatividade, de acordo com seus recursos e possibilidades, para que não se percam no meio do caminho sem atingir os necessários objetivos propostos.

\section{Considerações finais}

Percebe-se que não é fácil visualizar a contribuição do bibliotecário na formação do leitor. A contribuição não se resume em realizar hora do conto, indicar e emprestar livros.

Na verdade ela, a contribuição, está nas "entrelinhas" da mediação, da intervenção deste profissional na escola, no seu engajamento e comunicação na comunidade, como trabalha em parceria, sua maneira de organizar o espaço da biblioteca (organização do ambiente e tempo para frequência e leitura), ao receber seus usuários, na demonstração do amor pela leitura, na indicação de leituras, na forma em que lê uma história, como conta uma história e a escuta, ao apresentar um autor e se apresentar como bibliotecário leitor, não desistindo frente às dificuldades encontradas e criando oportunidades de leitura frente à vida escolar. 
Pode-se constatar que não há uma receita, um guia único, pois as pessoas e a realidade de cada escola não são idênticas. O que pode acontecer é indicar caminhos por meio de textos e experiências reveladas.

\section{Referências}

ALMEIDA JUNIOR, Oswaldo Francisco de. Bibliotecário escolar: seu perfil, seu fazer. In: SILVA, Rovilson José da; BORTOLIN, Sueli (Orgs.). Fazeres cotidianos na biblioteca escolar. São Paulo: Polis, 2006. p. 43-54. (Coleção Palavra-Chave, v.17).

BARROS, Maria Helena T. C. O bibliotecário e o ato de ler. In: SILVA, Ezequiel Theodoro (Org.). O bibliotecário e a análise dos problemas de leitura. Porto Alegre: Mercado Aberto, 1986. (Cadernos da ALB, 1).

BATTLES, Matthew. A conturbada história das bibliotecas. São Paulo: Planeta do Brasil, 2003.

BORTOLIN, Sueli. A leitura e o prazer de estar na biblioteca escolar. In: SILVA, Rovilson José da; BORTOLIN, Sueli (Org.). Fazeres cotidianos na biblioteca escolar. São Paulo: Polis, 2006. p. 65-72. (Coleção Palavra-Chave, v.17).

MARTINS, Elizandra; BORTOLIN, Sueli. O bibliotecário escolar "afinando" o foco na leitura. In: SILVA, Rovilson José da; BORTOLIN, Sueli (Org.). Fazeres cotidianos na biblioteca escolar. São Paulo: Polis, 2006. p. 33-42. (Coleção Palavra-Chave, v.17).

MAYRINK, Paulo Tarcísio; MORANDIN,Rosana Helena; VANALLI,Tereza Raquel. Avaliação de coleções da FDE em bibliotecas de escolas da região de Marília. Revista Brasileira de Biblioteconomia e Documentação, São Paulo, v.25, n.3/4, p.49-59, jul./dez. 1982.

OBATA, Regina Keiko. Biblioteca interativa: construção de novas relações entre biblioteca e educação. Revista Brasileira de Biblioteconomia e Documentação, São Paulo, nova série, v.1, n.1, p. 91-103, 1. ${ }^{\circ}$ sem. 1999.

SIDOTI, Ana Paula et al. Constituição do leitor. [2002?] Disponível em <http://www.lite.fae.unicamp.br/papet/2002/ep127/leitor.htm>. Acesso em: 20 jul. 2006.

SILVA, Ezequiel Theodoro da. Democratização da leitura: uma forma de despertar leitores. In: _ Conferências sobre leitura: trilogia pedagógica. Campinas: Autores Associados, 2003. p.15-37.

Possíveis contribuições dos bibliotecários à dinamização da leitura no Brasil. 1988. Palestra proferida no Encontro de Bibliotecários das Regiões Sudeste e Sul, promovido pela Coordenação de Desenvolvimento Técnico do SESC/DN, Florianópolis, 29.11.88. 
SILVA, Rovilson José. Formar leitores na escola. In: SILVA, Rovilson José da;

BORTOLIN, Sueli (Org.). Fazeres cotidianos na biblioteca escolar. São Paulo: Polis, 2006. p.73-78. (Coleção Palavra-Chave, v.17).

SILVA, Rovilson José da; BORTOLIN, Sueli. Reflexões sobre a leitura e a biblioteca escolar. In:

Fazeres cotidianos na biblioteca escolar. São Paulo: Polis, 2006. p.11-19. (Coleção Palavra-Chave, v.17). 